Анна Попова

ORCID: 0000-0001-8189-7267

Донецкий национальный университет

Донецк, Украина

\title{
ГЕНДЕРНЫЕ МОДЕЛИ ИСПОВЕДАЛЬНОЙ СТРАТЕГИИ В ИСПОВЕДИ СЫНА ВЕКА А. ДЕ МЮССЕ И ИСПОВЕДИ МОЛОДОЙ ДЕВУШКИ ЖОРЖ САНД
}

\author{
https://doi.org/10.34739/clit.2020.14.08
}

\author{
GENDER MODELS OF CONFESSIONAL STRATEGY \\ IN ALFRED DE MUSSET'S CONFESSION UN ENFANT DU SIÈCLE \\ AND GEORGE SAND'S CONFESSION D'UNE JEUNE FILLE
}

\begin{abstract}
The article deals with the peculiar features of the confessional strategy in the novels La Confession d'un enfant du siècle (1836) by Alfred de Musset and La Confession d'une jeune fille (1864) by George Sand. The author analyses correlation between the universal and the gender marked principles in the authors' style of the presentation of events. There have been revealed similarities at the level of the plot model (the story of a young man/woman growing up), the narrative organization (confession), the motives' structure (orphanhood, selfidentification, "sentimental education"), which have been determined by the influence of the genre tradition and the authors' Romantic worldview. At the same time, the differences in the composition, the criteria for the selection of material, the degree of frankness and self-esteem show the dependence of the confessional text on gender.
\end{abstract}

Keywords: George Sand, A. de Musset, confessional strategy, gender peculiarity

Истоки исповедального жанра лежат в религиозной культуре, в частности, в сфере клерикальной литературы. Христианство дало мощный импульс персонализации человека. Обращенность к его внутреннему миру, утверждение двойственности человеческой природы, фактически представляющей собой диалог-противостояние материально-телесного низа и духовного верха, свойственные христианской религии, создали в литературе предпосылки к глубокому и многостороннему изображению индивида во всем драматизме его существования. В Исповеди (400) Аврелия Августина 
ветхозаветный диалог человека с Творцом превращается в инструмент самопознания. Личностное Я раскрывается в общении с Ты Бога, в этом Я заключенном, а результатом погружения в себя становится изумление человека перед великой тайной, которой он является: «Не загадка ли я сам для себя?»1. При всей новизне подхода к изображению своей личности в динамике ее развития, сочинение епископа Иппонийского и по форме, и по содержанию продолжает оставаться в рамках религиозной традиции. Для автобиографических произведений последующих столетий характерен поступательный и неуклонный отход от религиозного аспекта проблемы самопознания как пути познания Бога в пользу светского и литературного, происходит т. н. «обмирщение» жанра. Уже в Истории моих бедствий (1129) Пьера Абеляра, общий тон диалога иной, по сравнению с Августиновой Исповедъю, он переходит в литературнохудожественную плоскость. Усиливается земное, личностное начало, появляется вымышленный адресат, автор уделяет больше внимания собственно биографии автора, личный опыт приобретает самостоятельную ценность. Еще дальше от христианской традиции общения человека с Богом отдаляется Мишель Монтень, чье творчество приходится на эпоху Возрождения. Исследуя самого себя, Монтень постигает не Бога в себе и себя в Боге, как Августин, а общие закономерности человеческой природы. Опьты (1580) уже предполагают широкого читателя, обращены к нему, как представителю той же «человеческой породы», что и сам автор. Окончательно из акта покаяния в инструмент самопознания исповедь превращается под пером Ж.-Ж. Руссо. Исповедь (1766-69) становится для него оправданием своей жизни и надежным гарантом спасения. Ее уникальность заключается также в том, что, сохраняя не только непременный формальный элемент исповедального жанра - наличие слушателя-оппонента, - но и эмоциональный накал исповеди, Руссо расширяет аудиторию до пределов всего человечества, а отсутствие прямых выводов дает каждому участнику этого диалога равную возможность вынести свое собственное суждение на основании предложенных автором фактов. По сути, Исповедъ завершает переход от церковного канона изображения человека как существа изначально греховного до обусловленного личностным началом в литературе оправдания права человеческого «Я» на самопознание и самоутверждение. Собственно, с появлением книги Руссо жанр литературной исповеди переживает кульминацию и впоследствии в своем чистом виде практически не встречается в западноевропейской

\footnotetext{
${ }^{1}$ А. Августин, Исповедь, [в того же:] Исповедъ: Абеляр П. История мохх бедствий,
} Москва 1992, с. 156. 
литературной традиции. Исповедальность становится компонентом стремительно развивающейся мемуарно-автобиографической литературы, а в начале XIX века в романтизме проявляется в новом жанре «личного» романа, или романа-исповеди.

К тому времени исповедь превращается в литературный факт, окончательно секуляризируется, лишившись сокровенности, присущей религиозному таинству, но сохранив свойственную религиозному жанру искренность, открытость и свободу самовыражения. При этом акцент сместился с покаяния и преображения как конечной цели исповеди на максимально возможную искренность, полноту самораскрытия. Вместе с тем появилось осознание личной ответственности не только перед Богом, но и перед людьми, которое стало основой нравственного пафоса литературной исповеди, а также причиной иного подхода к отбору жизненного материала. Гендерный аспект исповедальности актуализируется с включением в литературный процесс писателейженщин. Так, ряд исследователей отмечает, что, приступая к созданию Истории моей жизни (1854-55), Жорж Санд всегда помнит о том, что ее книга будет прочитана как написанная женщиной, поэтому здесь нет и намека на то, что могло бы скомпрометировать автора как жену и мать².

Сложившийся в «личном» романе особый тип исповедальности, когда лично пережитое используется автором в качестве художественного материала («хорошо можно изобразить только свое сердце, приписывая его другому»3), позволил решить эту проблему, поставив между Я автора и Я героя романную фабулу. Уступая Руссо в искренности, романтики на основе самоанализа создавали образы своих современников, «детей века». При очевидной индивидуализации героев, в их облике угадывается и общая психологическая доминанта эпохи, и существующие в обществе модели поведения, в том числе, гендерные. Последние находят выражение в стратегии исповедального дискурса, что может быть рассмотрено на примере двух романов - Исповедь сына века (1836) А. де Мюссе и Исповедь молодой девуики (1864) Жорж Санд.

\footnotetext{
2 Подробнее о мере искренности и принципах отбора материала в Истории моейжизни Жорж Санд см. в работах: Sara E. Murphy, Refusing to Confess: George Sand's Histoire de ma vie and the Novelization of Autobiographical Discourse, [в:] Correspondances. Ed. by Keith Busby, Amsterdam 1992, p. 157-164; Ch. Planté, George Sand. Fìls de JeanJacques, [в:] French studies ot the Eighteenth ans Nineteenth CenturiesGeorge Sand: Intertextualité et Polyphonie 1. Ed. by Nigel Harkness and Jacinta Wright, Oxford, Bern, Berlin, Bruxelles, Frankfurt am Main, New York, Wien 2010, p. 23-46.

3 F.-R. de Chateaubriand, Genie du Christianisme, Paris 1865, p. 84.
} 
Авторов этих двух текстов связывают близкие отношения, собственно, и ставшие биографической основой для романа Мюссе («Я не умру, не написав книги о себе и о тебе (главное - о тебе)»4. А произведение Жорж Санд, несмотря на несвойственное «личному» роману обилие персонажей и разветвленную, почти авантюрную фабулу, может быть прочитано как реплика Мюссе, женская модель самопознания, противопоставленная еe мужскому варианту, описанному в Исповеди сына века.

На первый взгляд у романов много общего, начиная с названия: La Confession d'un enfant du siècle и La Confession d'une jeune fille. В обоих случаях в заглавии присутствует слово «исповедь» (confession) и неопределенный артикль «un/une», указывающий, с одной стороны, на единичность, а, с другой, на то, что изображенный в романе герой один из многих в своем роде.

Сходна также композиция - оба романа представляют собой обрамленную исповедь-воспоминание с открытым финалом. Их действие разворачивается примерно в одну и ту же эпоху - первую треть XIX века. В обоих случаях годы рождения героев совпадают с авторскими (1810-й у Мюссе и 1804-й у Жорж Санд), что косвенно говорит о наличии биографического начала. И Октав, и Люсьена показаны в процессе взросления, перехода от детства к зрелости. Обоим на момент повествования чуть больше двадцати, а основные события разворачиваются, когда и Октаву, и Люсьене исполняется 19-20 лет. Примечательно, что первый кризис происходит у них в четырнадцать лет и связан с осознанием своей гендерной принадлежности: Октав, побуждаемый отцом выбрать будущую профессию, восклицает, простирая руки к одинокому тополю: «Нет, я буду не человеком какого-нибудь особого разряда, а просто человеком!»5 (в данном случае «hommе»6 - это еще и мужчина), а Люсиль, когда ее кузен Мариус предостерегает ее от опасности быть скомпрометированной, оставаясь наедине со своим учителем, вдруг понимает, что она женщина и может представлять матримониальный интерес. Второй кризис, знаменующий новый этап самоидентификации, в обоих случаях связан со смертью отца.

Вместе с тем, отличий между этими двумя текстами гораздо больше и лежат они как в повествовательной (обусловленной временной дистанцией в тридцать лет, и особенностями индивидуального художественного стиля писателей), так и в

4 G. Sand et A. de Musset, Correspondance, Monaco 1956, p. 159.

5 А. де Мюссе, Исповедъ сына, [в того же:] Исповедь сына века: Роман, новеллы, пьесы, стихотворения, Москва 2007, с. 61.

6 «je serai un homme, mais non une espèce d'homme particulière» - A. de Musset, La Confession d'un enfant du siècle, V. I, Paris 1836, p. 71. 
концептуальной плоскости. Возвращаясь к заголовочному комплексу, отметим, что уже в названиях задан совершенно разный эпический масштаб повествования - «сын века» у Мюссе и «девушка» у Жорж Санд. Несмотря на то, что взросление Люсьены, как и Октава, приходится на эпоху Реставрации, в романе об этих событиях упоминается только в связи $\mathrm{c}$ тайной рождения героини и притязаниями потомков маркиза де Валанжи на титул. Здесь нет, как в случае с Октавом, обусловленности личной трагедии крушением прежних моральных ориентиров и несовершенством нового миропорядка. Но хотя у Жорж Санд образ героини и не включен в широкий исторический контекст эпохи, в нем есть обобщение иного рода: история Люсьены представляет собой модель взросления молодой девушки в патриархальном мире.

Установка на искренность, без которой невозможна исповедь и которая становится критерием истины о субъекте, также по-разному реализуется у Мюссе и у Жорж Санд. При том, что оба подчеркивают свою неспособность лгать, проявляющуюся даже на физиологическом уровне (оба краснеют), искренность они понимают по-разному (Октав: «Я никогда не умел лгать, и всякий раз, как мне хотелось скрыть чтонибудь, лицо мое неизменно выдавало меня»7; Люсьена: «Фрюманс увидел, что я покраснела, и ласково стал меня расспрашивать. Лгать я не умела и призналась...» $\left.{ }^{8}\right)$. Для Октава это прежде всего свидетельство правдивости его слов, подлинности и полноты раскаяния. Самообнажаясь, герой тем самым признает свою вину, а страдание, которое он при этом испытывает, вызывает сочувствие и сострадание адресата исповеди: «Она видела мои страдания и не могла не жалеть меня» 9 .

Искренность Люсьены иного рода. В отличие от Октава, который то и дело взывает к Богу в надежде на избавление от тяжести греха, она себе главный и самый строгий судья:

Я сейчас стараюсь искупить прошлые свои заблуждения, прошлые притязания на какое-то идеальное счастье. (...) Знаю, бог простил мне прежние мои грехи, потому что, увидев, как мучается Женни, узнав, что значит страх утраты дорогого человека, я прокляла свою гордыню и отказалась от тщеславных мечтаний ${ }^{10}$.

\footnotetext{
7 А. де Мюссе, op. cit., с. 101.

8 Ж. Санд, Исповедь молодой девушки, [в:] Собрание сочинений. В 9-ти т. Т. 8, Ленинград 1974, с. 375 .

9 А. де Мюссе, op. cit., с. 170.

10 Ж. Санд, op. cit., с. 599.
} 
Если героиня о чем и сожалеет, то лишь об обидах, невольно нанесенных ею другим людям из-за неопытности и неведения и о заблуждениях, вызванных той же причиной. Отсутствие опыта у девушки, воспитанной в совершенном неведении относительно многих сторон жизни, табуированность всего, что связано с телесной и чувственной сферой, предстает в романе едва ли не главным источником ошибок. Люсьена то и дело повторяет: «если бы сознавала, что я делаю»11, «сама того не зная»12, «поступки мои были почти бессознательными» ${ }^{33}$ и т. п. Ее исповедь становится средством уяснить для себя самой мотивы своих поступков, какими бы смешными или постыдными они ни были.

Люсьена не считает нужным никого убеждать в подлинности своего рассказа и даже не сомневается в своей нравственной чистоте и невинности, которая в тексте характеризуется как полная и совершенная (complète, parfaite). В этом угадывается отношение самой Жорж Санд к исповедальному слову. Именно так поступает юная Аврора во время исповеди деревенскому священнику. На неделикатные вопросы о ее предполагаемых любовных переживаниях она отвечает, что раз не говорит ему об этом, значит, не считает себя ни в чем виноватой: «је ne comprends pas que vous doutiez de ma sincérité. (...) J'eusse dû vous dire que cela ne vous regardait pas»14 (мне непонятно, почему вы сомневаетесь в моей искренности (...) Вынуждена вам сказать, что вас это не касается 15 ). Точно так же она подходит и к рассказу об отдельных эпизодах своей жизни в Истории моей жизни, практически повторяя упомянутую формулировку в главе, посвященной драматическим отношениям с матерью: «Le reste ne regarde que moi»16 (Остальное касается только меня) ${ }^{17}$. Честность прежде всего с самой собой и для Люсьены является главным критерием подлинности исповеди. Она не определяется наличием в ней постыдных откровений или пикантных подробностей.

Думается, что различия в исповедальной стратегии обусловлены также разностью адресатов. У Мюссе это некие неназванные читатели, но позволим себе предположить, что речь идет,

\footnotetext{
${ }^{11}$ Ibidem, c. 393.

12 Ibidem, c. 398.

13 Ibidem, c. 443.

14 G. Sand, Histoire de ma vie, V. II, Paris 2001, p. 133.

15 Здесь и далее, кроме особо оговоренных случаев, перевод мой - А.П.

${ }^{16}$ G. Sand, op. cit., p. 208.

17 Подробнее о специфике исповедальности в Истории моей жизни Жорж Санд см.: А.В. Попова, Исповедальная интенция в «Истории моей жизни» Жорж Санд, [в:] Автобиографические сочинения в междисциплинарном исследовательском пространстве: Люди, тексты, практики, ред. Ю.П. Зарецкий, Е.К. Карпенко, 3.В. Шушпанова, Москва 2017, с. 365-384.
} 
прежде всего, о женской аудитории (в пользу этого говорит и процитированная выше фраза из письма Жорж Санд, к которой, в первую очередь, и обращена исповедь). Это объясняет акцентирование темы детства, сиротства, болезни, изменчивости эмоциональных реакций, общей невротичности героя. Герой обращается к аудитории, условно говоря, на понятном ей языке, предстает перед ней в образе жертвы, взыскуя безусловного материнского понимания и снисхождения. Надрывность исповеди на композиционном уровне проявляется во фрагментаризации текста, когда, по словам Л.А. Мироненко «Разрозненные эпизоды, ситуации, персонажи как бы тонут в эмоциональной до взвинченности исповедисамоанализе» ${ }^{8}$.

Люсьена адресует исповедь потенциальному супругу с тем, чтобы максимально полно раскрыть перед ним свой внутренний мир, показать достоинства и недостатки своей натуры и этим дать ему возможность совершить осознанный выбор, что в будущем станет залогом счастливого брака. Обращаясь к мужчине, Люсьена сознательно акцентирует свою способность рационально мыслить, смирять эмоции. Если Октав показывает свою слабость, то Люсьена демонстрирует силу, умение мыслить здраво: «способность рассуждать была во мне настолько развита, что я старалась во всем отдавать себе отчет» ${ }^{19}$. Композиционно эта интенция находит выражение в линейной организации повествования, его подробной детализации: героиня хочет «почти день за днем, шаг за шагом, час за часом восстановить свою жизнь» ${ }^{20}$.

Показательно, что герой Мюссе для ощущения полноты бытия, собственной завершенности нуждается в присутствии рядом с ним возлюбленной, подруги, матери: «я чувствовал, что ее любовь несет мне гибель, но жить без этой женщины я не мог»21; «ей не нужна больше твоя жизнь, и, значит, она не нужна никому» 22 . Героиня же Санд, напротив, испытывает двойственное чувство, постоянно пребывая в компании своего кузена Мариуса, чье присутствие не позволяет ей до конца понять себя: «Он препятствовал мне быть собою, и я не знала бы, что мне делать с собой без него. Я часто испытывала потребность уйти от него и вновь обрести себя, но через несколько часов мне его уже опять недоставало» 23 (в оригинале эта

18 Л.А. Мироненко, Художественный мир «личного романа»: от Шатобриана до Фромантена, Донецк 1999, с. 144.

19 Ж. Санд, op. cit., с. 520.

${ }^{20}$ Ibidem, c. 625.

${ }^{21}$ А. де Мюссе, op. cit., с. 57.

22 Ibidem, c. 289.

23 Ж. Санд, op. cit., 331. 
мысль звучит более отчетливо: «il m'arrachait à ma personnalité. Il m'empêchait d'être moi»24). Взросление, c eе точки зрения, знаменуется как раз осознанием собственной автономности, обретением полноты, завершенности: «вчерашний ребенок переступает порог жизни. Теперь он знает истинный ее смысл или пытается его узнать, заглядывая в собственное сердце, становится законченным существом или стремится им стать» ${ }^{25}$. Не приемлет она и жалости по отношении к себе, заключая исповедь словами: «Я не чувствую и никогда не почувствую себя несчастной, потому что завоевала право уважать себя и верить в собственное мужество» 26 .

Мотив взросления в обеих исповедях сопряжен с проблемой самоидентификации. В обоих случаях отправной точкой в поиске себя становится смерть отца - любящего и заботливого у Октава, безразличного к судьбе дочери у Люсьены. Герои оказываются в зеркальной ситуации: Октав наследует имя и поместье, а Люсьена теряет все права и на имя, и на собственность. Дальнейшие их действия также носят диаметрально противоположный характер. В то время как Октав, поселившись в отцовском доме и окружив себя отцовскими вещами, примеривает на себя его идентичность (вплоть до того, что следует его распорядку дня и начинает вести дневник, велев «переплести точно такую же тетрадь, какая была у отца»27), Люсьена, отказавшись от унизительных, по ее мнению, компромиссов с наследниками, в труде и самоотречении обретает истинный смысл жизни («подлинное страдание вдохнуло в меня и подлинную силу» ${ }^{28}$ ), занимает независимое положение, которое, по ее мнению, «стоит любых дворянских привилегий»29.

Тот факт, что героиня не сразу приняла предложение очарованного ее совершенствами английского адвоката Мак-Аллана, а прежде решила раскрыть перед ним свой внутренний мир («все вытащила наружу, все подвергла анализу» 30 ), свидетельствует о формировании в европейской культуре XIX века нового типа отношений между полами, когда женщине уже недостаточно было оставаться только лишь объектом любовного влечения мужчины. Брак представляется героине своеобразной формой товарищества, основанного на искренности и взаимном доверии. Отсюда и желание открыться партнеру не для признаний в чем-то неблаговидном, а для

\footnotetext{
${ }^{24}$ G. Sand, La confession d'une jeune fille, V. I. Paris 1865, p. 95.

25 Ж. Санд, op. cit., c. 520.

${ }^{26}$ Ibidem, c. 625 .

27 А. де Мюссе, op. cit., c. 145.

28 Ж. Санд, op. cit., c. 599.

${ }^{29}$ Ibidem, c. 615 .

30 Ibidem, c. 625 .
} 
того, чтобы между любящими не осталось никакой недосказанности. При этом Люсьена категорически не приемлет жалости и снисхождения к себе: «Мое волнение возросло еще больше, когда я увидела, что иностранец заметил мое смущение и жалеет меня. Это меня оскорбляло и в то же время приводило в негодование, ибо я отнюдь того не заслуживала» ${ }^{11}$. Она соглашается еще раз выслушать Мак-Аллана лишь когда обретает полную независимость и может рассчитывать на серьезное к себе отношение, поскольку «завоевала право уважать себя»32.

В исповедальной стратегии, использованной Жорж Санд в романе «Исповедь молодой девушки», находит отражение как индивидуальная установка на открытость автора читателю, на искренность описываемых им чувств и суждений, которыми он готов поделиться с ним для всеобщего блага, так и полемика с патерналистскими установками современного автору общества. Создавая свой роман почти тридцать лет спустя после публикации «Исповеди сына века» Мюссе, писательница полемически заостряет исповедальное слово своей героини, противопоставляя его голосу болезненного и слабого «сына века». Тем самым она утверждает свой идеал женщины и показывает его преимущества по отношению к мужскому типу личности, сформированному эпохой.

\section{Литература}

Chateaubriand F.-R. de, Genie du Christianisme, Paris 1865.

Murphy S.E., Refusing to Confess: George Sand's Histoire de ma vie and the Novelization of Autobiographical Discourse, [в:] Correspondances. Ed. by Keith Busby, Amsterdam 1992, p. 157-164.

Musset A. de, La Confession d'un enfant du siècle, en 2 vol., Paris 1836.

Planté Ch., George Sand. Fils de Jean-Jacques, [в:] French studies ot the Eighteenth ans Nineteenth Centuries George Sand: Intertextualité et Polyphonie 1, ed. by Nigel Harkness and Jacinta Wright, Oxford, Bern, Berlin, Bruxelles, Frankfurt am Main, New York, Wien 2010, p. 23-46.

Sand G. et A. de Musset, Correspondance, Monaco 1956.

Sand G., Histoire de ma vie, en 2 vol., Paris 2001.

Sand G., La confession d'une jeune fille, en 2 vol., Paris 1865.

Августин А., Исповедь, [в того же:] Исповедь: Абеляр П. История моих бедствий, Москва 1992, с. 7-222.

Мироненко Л.А., Художественный мир «личного романа»: от Шатобриана до Фромантена, Донецк 1999.

${ }^{31}$ Ж. Санд, op. cit., c. 450.

${ }^{32}$ Ibidem, c. 625. 
Мюссе А., Исповедь сына века, [в того же:] Исповедь сына века: Роман, новеллы, пьесы, стихотворения, Москва 2007, с. 33-304.

Попова А.В., Исповедальная интенция в «Истории моей жизни» Жорж Санд, [в:] Автобиографические сочинения в междисциплинарном исследовательском пространстве: Люди, тексты, практики, ред. Ю.П. Зарецкий, Е.К. Карпенко, З.В. Шушпанова, Москва 2017, c. 365-384.

Санд Ж., Исповедъ молодой девушки, [в:] Ж. Санд, Собрание сочинений. В 9-ти т., Т. 8, Ленинград 1974, с. 277-626.

\section{References}

Chateaubriand F.-R. de, Genie du Christianisme, Paris 1865.

Murphy S.E., Refusing to Confess: George Sand's Histoire de ma vie and the Novelization of Autobiographical Discourse, [в:] Correspondances. Ed. by Keith Busby, Amsterdam 1992, p. 157-164.

Musset A. de, La Confession d'un enfant du siècle, en 2 vol., Paris 1836.

Planté Ch., George Sand. Fils de Jean-Jacques, [в:] French studies ot the Eighteenth ans Nineteenth Centuries George Sand: Intertextualité et Polyphonie 1, ed. by Nigel Harkness and Jacinta Wright, Oxford, Bern, Berlin, Bruxelles, Frankfurt am Main, New York, Wien 2010, p. 23-46.

Sand G. et A. de Musset, Correspondance, Monaco 1956.

Sand G., Histoire de ma vie, en 2 vol., Paris 2001.

Sand G., La confession d'une jeune fille, en 2 vol., Paris 1865.

Avgustin A., Ispoved', [v togo že:] Ispoved': Abelâr P. Istoriâ moih bedstuij, Moskva 1992, s. 7-222.

Mironenko L.A., Hudožestvennyj mir «ličnogo romana»: ot Šatobriana do Fromantena, Doneck 1999.

Mûsse A., Ispoved' syna veka, [v togo že:] Ispoved' syna veka: Roman,novelly, p'esy, stihotvoreniâ, Moskva 2007, s. 33-304.

Popova A.V., Ispovedal'nâ̂ intenciâ $v$ «Istorii moej žizni» Žorž Sand, [v:] Avtobiografičeskie sočineniâ v meždisciplinarnom issledovatel'skom prostranstve: Lûdi, teksty, praktiki, red. U..P. Zareckij, E.K. Karpenko, Z.V. Šušpanova, Moskva 2017, s. 365-384.

Sand Ž., Ispoved' molodoj devuški, [v:] Ž. Sand, Sobranie sočinenij. V 9-ti t., T. 8, Leningrad 1974, s. 277-626. 